\section{Tomato second cycle hybrids as a source of genetic variability for fruit quality traits}

\author{
Pereira da Costa $\mathrm{JH}^{1,2^{*}}$, Rodríguez $\mathrm{GR}^{1,2}$, Liberatti DR ${ }^{2}$, Mahuad \\ $\mathrm{SL}^{2}$, Marchionni Basté $\mathrm{E}^{2}$, Picardi $\mathrm{LA}^{2,3}$, Zorzoli $\mathrm{R}^{2,3}$ and Pratta \\ $\mathrm{GR}^{1,2}$
}

\begin{abstract}
The objective of this study was to investigate the phenotypic and molecular variability in a $F_{2}$ generation derived from a SCH (Second Cycle Hybrid) in order to detect QTLS for some fruit traits of tomato. Genome coverage at different levels was achieved by three types of molecular markers (polypeptides, sequence-related amplified polymorphism-SRAP and amplified restriction fragment polymorphism - AFLP). Different degrees of polymorphism were detected by SRAP and AFLP at the DNA structure level and also by polypeptides at the DNA expression level. The first two markers, associated with phenotypic variation, detected QTLs involved in important agronomic traits such as fruit shelf life, soluble solids content, $\mathrm{pH}$, and titratable acidity. New gene blocks originated by recombination during the first cycle of crossing were detected. This study confirmed that the observed phenotypic differences represent a new gene rearrangement and that these new gene blocks are responsible for the presence of the genetic variability detected for these traits.
\end{abstract}

Keywords: Recombinant inbred lines, Solanum lycopersicum, genetic recombination, gene blocks.

\section{INTRODUCTION}

In the last 30 years, significant progress has been made in tomato breeding by replacing open-pollinated varieties by hybrids (Figueiredo et al. 2015). A physiological plateau was reached when both yield and fruit quality had been improved (Grandillo et al. 1999). However, the advent of genomics has transformed breeding strategies. As a result, the improvement of tomato cultivars is expected to continue in the future. Recombinant Inbred Lines (RILs) allow increase the genetic variability by recombination and chromosome rearrangements, introducing new gene blocks. One way to profit from these new rearrangements is to develop Second Cycle Hybrids $(\mathrm{SCH})$. These genotypes are generated by hybridization among RILs (Hills et al. 2003, Ipsilandis et al. 2006). According to Pratta et al. (2003) and Pereira da Costa et al. (2009), Solanum pimpinellifolium $L$. could be an appropriate parental genotype to improve fruit quality traits. These authors found that its hybrids with cultivated tomato had longer fruit shelf life compared to commercial cultivars and also better fruit quality in terms of color, texture and flavor. Though S. lycopersicum L. and S. pimpinellifolium have significant phenotypic differences, only minor variation was found among them at the genomic level (about $0.6 \%$ ) (Tomato Genome Consortium 2012). It can be postulated that these differences are due to protein
Crop Breeding and Applied Biotechnology 16: 289-297, 2016 Brazilian Society of Plant Breeding. Printed in Brazil http://dx.doi.org/10.1590/198470332016v16n4a44
${ }^{*}$ Corresponding author:
E-mail: jpereira@unr.edu.ar

Received: 13 April 2015 Accepted: 03 May 2016

${ }^{1}$ IICAR-CONICET (Instituto de Investigaciones en Ciencias Agrarias de Rosario - Consejo Nacional de Investigaciones Científicas y Técnicas), Universidad Nacional de Rosario, Facultad de Ciencias Agrarias, Campo Experimental JF Villarino CC 14 (S2125ZAA), Zavalla, Santa Fe, Argentina2 Universidad Nacional de Rosario

3 IICAR-CONICET, CIUNR (Consejo de Investigaciones de la Universidad Nacional de Rosario), Universidad Nacional de Rosario 
functions (Michael and Alba 2012) and consequently to transcriptome regulation. As Giovannoni (2004) pointed out, the fruit quality could be conditioned by the developmental stage of the fruits at harvest time.

Different techniques have generated large amounts of data of gene expression during the development of climacteric and non-climacteric tomato fruits (Aharoni and O'Connell 2002, Henniget al. 2004, Grimpletet al. 2005, Moyle et al. 2005, Terrier et al. 2005). Carotenoid pigment accumulation and fruit softening distinguish at least two ripening stages: mature green and red ripe (Rick 1978, Giovannoni 2004). Although the polymorphism of polypeptide profiles is relatively low, they have been successfully used as molecular markers in various species to characterize genotypes or biological processes (Castro et al. 2006, Rodríguez et al. 2011).

Sequence-related amplified polymorphism markers (SRAPs) are DNA markers that preferentially amplify the expressed genomic regions (Li and Quiros 2001). These markers have been previously used in different species (Ruiz et al. 2005, Cravero et al. 2007, Mahuad et al. 2013). Other commonly used DNA markers are AFLP (Amplified Fragment Length Polymorphism), uniformly distributed in the tomato genome (Saliba-Colombaniet al. 2001), with a high chromosome coverage. Therefore, they were used to generate various inter- and intraspecific maps as well as to assess the genetic diversity of tomato cultivars, for genotyping (fingerprinting) and to detect QTLs of different fruit traits in interspecific crosses (Zhang and Stommel 2001, Lecomte et al. 2004, Pratta et al. 2011). Due to the different nature of genome coverage (expressed regions vs. random regions) of these three types of molecular markers (polypeptides and SRAP vs. AFLP), they could be interesting molecular tools to detect QTLs for fruit quality traits. As pointed out, the genetic recombination that occurs during the generation of the $\mathrm{SCH}$ s would produce genetic variability for these traits. Consequently, the aim of this study was to assess the amount of genetic variability at the phenotypic and molecular levels in the $F_{2}$ generation derived from a SCH and also to detect QTLs for some fruit quality traits. In addition, we demonstrated that new gene blocks were originated by recombination during the first cycle of crossing and that they were preserved even in the $F_{2}$ derived from the selfed $\mathrm{SCH}$.

\section{MATERIAL AND METHODS}

\section{Plant material}

By antagonistic-divergent selection for weight and fruit shelf life, Rodríguez et al. (2006) obtained 17 RILs. These were derived from the $F_{2}$ generation of an interspecific cross between LA722 of S. pimpinellifolium and the Argentinean cultivar Caimanta of $S$. Iycopersicum (first-cycle parental genotypes). The RILs ToUNR1, ToUNR8, ToUNR9, ToUNR15, and ToUNR18 were selected based on their combining ability. Then the five RILs were crossed according to a diallel cross (Model II without reciprocal crosses) to select the best $\mathrm{SCH}$ among the 10 possible $\mathrm{F}_{1} \mathrm{~s}$ to initiate a new breeding process. Due to the high values of specific combining ability for fruit weight and shelf life and the significant values of general combining ability of its parents, the hybrid ToUNR9 $x$ ToUNR15 was selected to obtain the segregating $F_{2}$ population by selfing (Marchionni Basté et al. 2010). Fifteen plants of each parental genotype and the $F_{1}$ and $180 F_{2}$ plants were assessed in a greenhouse in a completely randomized design.

\section{Phenotypic analysis}

The following fruit traits were evaluated: weight $(\mathrm{W} ; \mathrm{g})$, diameter $(\mathrm{D} ; \mathrm{cm})$, height $(\mathrm{H} ; \mathrm{cm})$, shape (Sh; height/diameter), and shelf life (SL; in days from harvest to fruit softening or excessive wrinkling), following the methodology proposed by Garg et al. (2008). In addition, the soluble solids content (SS, ${ }^{\circ}$ Brix), measured with a hand refractometer, pH, titratable acidity of the homogenized juice ( $T A, g$ ), pericarp thickness (PT, $m m$ ), locule number (LN), and fruit firmness (F), on the equatorial plane in two opposite areas of the fruit measured with a durometer type Shore A (Durofel DFT100, 0.10 $\mathrm{cm}^{2}$ ) were assessed.

\section{Molecular analysis}

\section{Pericarp polypeptide profiles}

Total pericarp proteins were extracted from fruits harvested at two ripening stages: Mature Green (MG, at least 10\% of the fruit surface red) and Red Ripe (RR, $90 \%$ of the fruit surface red). Three independent pericarp samples (fruits from 
three different plants) per parental genotype and $F_{1}$, and one sample per $F_{2}$ plant were extracted from fruit harvested at each ripening stage. Proteins were extracted and resolved on SDS-PAGE following the protocol proposed by Rodríguez et al. (2008). Equal amounts of polypeptides (20 ug) were run for $1.5 \mathrm{~h}$ at a constant current of $35 \mathrm{~mA}$ on denaturing polyacrylamide gels ( $12 \% \mathrm{v} / \mathrm{v})$. Gels were stained with a $0.1 \%$ solution of Coomassie Brilliant Blue R-250 and destained with boiling water, scanned and analyzed with software Gelpro Analyzer 3.0.

\section{DNA Markers}

Young leaves were collected from the parents, $F_{1}$ and each $F_{2}$ plant and stored at $-80{ }^{\circ} \mathrm{C}$. The DNA was extracted with a commercial kit (Wizard ${ }^{\circledR}$ Genomic DNA Purification Kit of Promega ${ }^{\circledR}$ ). PCR amplifications were performed in duplicate for parental genotypes and $\mathrm{F}_{1}$.

\section{Sequence-Related Amplified Polymorphism (SRAP)}

Four of the primer combinations previously selected for their high level of polymorphisms (Mahuad et al. 2013) were used to characterize the parental genotypes, and $F_{1}$ and $F_{2}$ plants. The amplification protocol proposed by $L i$ and Quiros (2001) was used with some modifications, as described by Mahuad et al. (2013). The bands were codified with a number (SI, SII, SIII, or SIV), according to the primer combination, followed by another number indicating the order of the band on the gels (e.g. SIV.26).

\section{Amplified Fragment Length Polymorphism (AFLP)}

Six AFLP primer combinations selected for their high level of polymorphism among parental genotypes (Liberatti et al. 2013) were used. The AFLP profiles were obtained following the amplification protocol proposed by Liberatti et al. (2013). The bands were codified with a capital letter indicating the primer combination followed by a number indicating the position of the band on the gels (e.g. X4)

\section{Statistical Analysis}

Normal distribution of each trait was tested by the Shapiro-Wilk test (Shapiro and Wilk 1965). The mean values of parental genotypes and $\mathrm{F}_{1}$ were compared with a $t$-Student test (Snedecor 1964). Broad-sense heritability $\left(H^{2}, H^{2}=\sigma_{g}^{2} / \sigma_{p}^{2}\right)$, where $\sigma_{g}^{2}$ is genetic variance and $\sigma_{p}^{2}$ is phenotypic variance) was calculated using variance components from ANOVA for a completely randomized design, according to Falconer and Mackay (1996). All statistical analyses were performed with software InfoStat Version 1.0 (Di Rienzo et al. 2001). With a view to the dominant nature of all molecular markers used in this study (polypeptide profiles, SRAP and AFLP), a $\chi^{2}$ test (Snedecor 1964) was used to verify the expected segregation of 3:1 (presence: absence) in the $F_{2}$ generation. Only bands with Mendelian inheritance in parents and $F_{2}$ were taken into account for the QTL detection. The de novo bands (present in the first-cycle but not second-cycle parental genotypes and vice versa) were evaluated according to Liberatti et al. (2013). The association between molecular markers and fruit quality traits was analyzed by the single point method (single point analysis) (Tanksley1993). One-way ANOVA was performed with markers as classification variables. All markers with Mendelian inheritance were used to determine the existence of gene blocks. The LOD threshold for accepting a linkage group (LG) was 3.0, estimated by software JoinMap4.0, with the following settings: $\operatorname{Rec}=0.40, \mathrm{LOD}=3.0$ and Jump $=5$. Recombination values were converted to genetic distances using the Kosambi (1943) mapping functions.

\section{RESULTS AND DICUSSION}

All phenotypic traits had normal distribution. The second cycle parental genotypes (ToUNR15 and ToUNR9) were significantly different for all traits except for fruit shelf life and firmness (Table 1). The results for weight and shelf life were consistent with those reported by Rodríguez et al. (2006), who characterized ToUNR9 as a genotype with short shelf life and low fruit weight and ToUNR15 as one with short shelf life and high fruit weight (Table 1). However, the frequency distribution in the $F_{2}$ (ToUNR15 x ToUNR9) generation for fruit shelf life (Figure 1e) shows wide phenotypic variation despite the similarity of the parental genotypes values. Even though $\mathrm{H}^{2}$ was $0.38 \pm 0.02$ for shelf life, transgressive segregation was observed in the $F_{2}$ generation (Figure 1e), indicating that QTLs for shelf life, and other attributes with very high $\mathrm{H}^{2}$ values (SS, $\mathrm{pH}$ and TA), could be detected in this population (see Table 1, shown in gray). When the polypeptide 
Table 1. Mean values, standard error for each evaluated traits in second cycle parental genotypes (ToUNR15 and ToUNR9), $F_{1}$ and $F_{2}$ generation and broad-sense heritability $\left(H^{2}\right)$

\begin{tabular}{lccccc}
\hline Fruit traits & ToUNR15 & ToUNR9 & $\mathbf{F}_{1}(\mathbf{1 5 \times 9})$ & $\mathbf{F}_{2}(\mathbf{1 5 \times 9 )}$ & $H^{2}$ \\
\hline D $(\mathrm{cm})$ & $3.42 \pm 0.09 \mathrm{c}$ & $1.95 \pm 0.06 \mathrm{a}$ & $2.85 \pm 0.04 \mathrm{~b}$ & $2.66 \pm 0.03$ & $0.63 \pm 0.02^{* * *}$ \\
H (cm) & $2.90 \pm 0.07 \mathrm{c}$ & $1.75 \pm 0.04 \mathrm{a}$ & $2.53 \pm 0.03 \mathrm{~b}$ & $2.39 \pm 0.02$ & $0.62 \pm 0.06^{* * *}$ \\
Sh & $0.85 \pm 0.02 \mathrm{a}$ & $0.90 \pm 0.01 \mathrm{~b}$ & $0.90 \pm 0.01 \mathrm{~b}$ & $0.91 \pm 0.01$ & $0.24 \pm 0.01^{* * *}$ \\
W (g) & $21.59 \pm 1.04 \mathrm{c}$ & $4.49 \pm 0.32 \mathrm{a}$ & $12.95 \pm 0.32 \mathrm{~b}$ & $10.84 \pm 0.36$ & $0.63 \pm 0.02^{* * *}$ \\
SL (days) & $15.13 \pm 1.49 \mathrm{a}$ & $15.39 \pm 0.43 \mathrm{a}$ & $16.37 \pm 0.84 \mathrm{a}$ & $16.22 \pm 0.28$ & $0.38 \pm 0.02^{* * *}$ \\
SS ( ${ }^{\circ}$ Brix) & $6.84 \pm 0.11 \mathrm{~b}$ & $5.07 \pm 0.06 \mathrm{a}$ & $7.20 \pm 0.07 \mathrm{~b}$ & $8.38 \pm 0.07$ & $0.85 \pm 0.02^{* * *}$ \\
pH & $4.84 \pm 0.05 \mathrm{~b}$ & $4.40 \pm 0.02 \mathrm{a}$ & $4.74 \pm 0.04 \mathrm{ab}$ & $4.68 \pm 0.01$ & $0.73 \pm 0.02^{* * *}$ \\
TA (g) & $0.31 \pm 0.01 \mathrm{a}$ & $0.43 \pm 0.02 \mathrm{~b}$ & $0.31 \pm 0.02 \mathrm{a}$ & $0.41 \pm 0.01$ & $0.78 \pm 0.06^{* * *}$ \\
F & $46.70 \pm 0.96 \mathrm{a}$ & $50.50 \pm 0.61 \mathrm{ab}$ & $51.76 \pm 1.50 \mathrm{~b}$ & $51.80 \pm 0.28$ & $0.52 \pm 0.03^{* * *}$ \\
LN & $4.42 \pm 0.22 \mathrm{c}$ & $2.00 \pm 0.00 \mathrm{a}$ & $2.95 \pm 0.11 \mathrm{~b}$ & $2.60 \pm 0.06$ & $0.48 \pm 0.02^{* * *}$ \\
PT & $0.39 \pm 0.02 \mathrm{c}$ & $0.19 \pm 0.01 \mathrm{a}$ & $0.29 \pm 0.02 \mathrm{~b}$ & $0.25 \pm 0.01$ & $0.67 \pm 0.02^{* * *}$ \\
\hline
\end{tabular}

D: diameter. H: height. Sh: shape. W: weight. SL: shelf life. SS: soluble solids content. TA: titratable acidity. F: firmness. LN: locule number. PT: pericarp thickness. Different letters indicate significant differences $(p<0.05)$

${ }^{* * *} p<0.001$

profiles of the second cycle parental genotypes ToUNR15 and ToUNR9 were compared, $27 \%$ and $8 \%$ of polymorphism were found at the mature-green and red-ripe stages, respectively. A high number of monomorphic bands were found at both ripening stages. Perhaps the selection process to obtain these RILs fixed the same alleles in some loci in the parental genotypes ToUNR15 and ToUNR9. No bands with Mendelian inheritance were found at the mature-green stage, but only one polypeptide of $75.6 \mathrm{kDa}$ with Mendelian inheritance was found at the red-ripe stage, though without any association with a phenotypic trait. These results indicated that the phenotypic differences between parents have no correlation with the polymorphism in polypeptide profiles. These kinds of molecular markers were useless to detect associations among polypeptide profiles and phenotypic traits in this genetic background generated by crossing ToUNR15 with ToUNR9. Other authors (Rodríguez et al. 2011, Pereira da Costa et al. 2014) detected QTLs by polypeptide profiles in other genetic backgrounds. Probably the parental genotypes for those studies were genetically more divergent than the RILs studied here.

A different situation was observed when SRAP markers were analyzed. A total of 214 SRAP bands were detected between the second cycle parental genotypes and the $F_{2}$ generation. A mean of 53 bands was detected by primer combinations. The combinations 2 and 4 were the most polymorphic (percentages ranged from $29.7 \%$ to $22.4 \%$ ). The mean number of bands detected by SRAP primer combinations was consistent with those reported by Mahuad et al. (2013), Pereira da Costa et al. (2014) and Ruiz et al. (2005). Nine bands with Mendelian inheritance were used for the association analysis. A total of 9 QTLs $(p<0.01)$ were found (Table $2 A)$. The proportion of phenotypic variance explained by each QTL ranged between 5 and $10 \%$. QTLs for soluble solids content, $\mathrm{pH}$, pericarp thinness and fruit height were detected (Table 2A). These results support the hypothesis of Mahuad et al. (2013), suggesting that it would be possible to find SRAP markers associated with tomato fruit quality traits because a high consensus was observed between molecular and phenotypic diversity when a diallel design of 5 RILs and their hybrids was evaluated. The presence of fragment SIV.7 $(\mathrm{p}<0.002)$, originated from ToUNR15, produced a decrease in SS and pH. A high soluble solids content is a desirable trait in breeding programs for being associated with a better fruit flavor (Stevens et al. 1979). In all cases, the SRAP bands of ToUNR9 were associated with an increase in sugar content, while the SRAP bands inherited from ToUNR15 had the opposite effect (Table 2A). These results were expected according to the parental values for the traits. For fruit height, the effect of band SI.55 was consistent with the phenotype observed in second-cycle parental genotypes. Accordingly, ToUNR9 had fruits with smaller height and size (Table1) and contributed to one SRAP band that diminished the mean values of these traits. These results demonstrate that the selection by RILs development fixed alleles in ToUNR15 andToUNR9 with opposite effects on fruit size and soluble solids content.

A total of 735 AFLP bands were detected of which 496 (67\%) were polymorphic. Mendelian inheritance was confirmed for 19 bands (4\%) and 13 QTLs were detected by AFLP markers. One QTL (X4, $p=0.001)$ for fruit shelf life decreased the mean value in the plants with this band. This QTL was contributed by To UNR15 (Table 2B).

Most associations detected by AFLP markers were related to the traits with greatest genetic variability in $\mathrm{F}_{2}$, i.e. SS, 
a

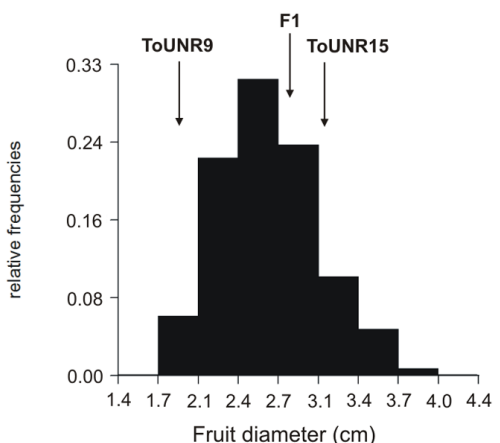

d

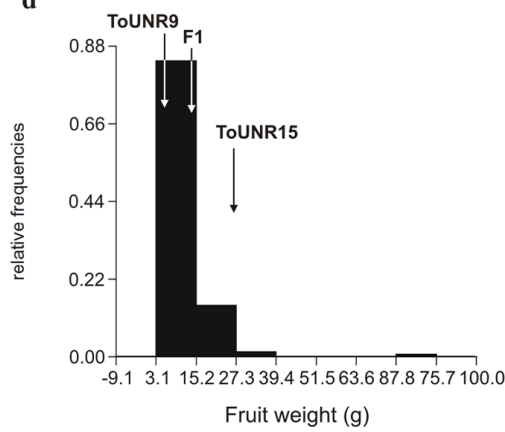

g

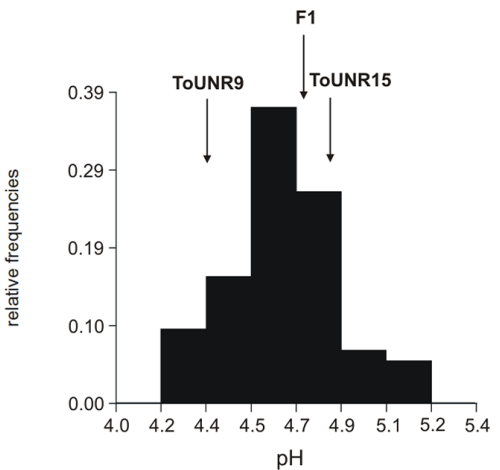

$\mathbf{j}$

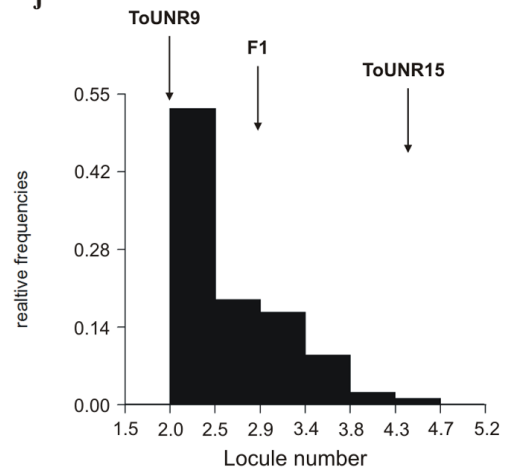

b

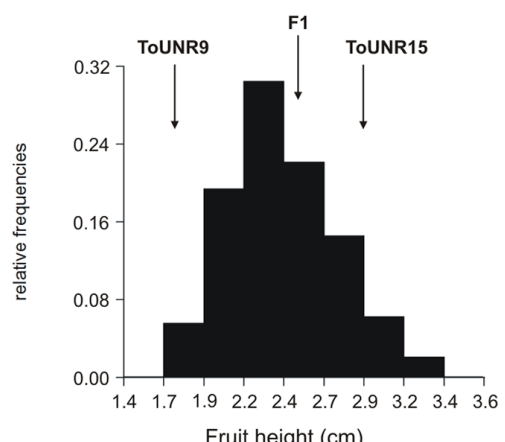

e

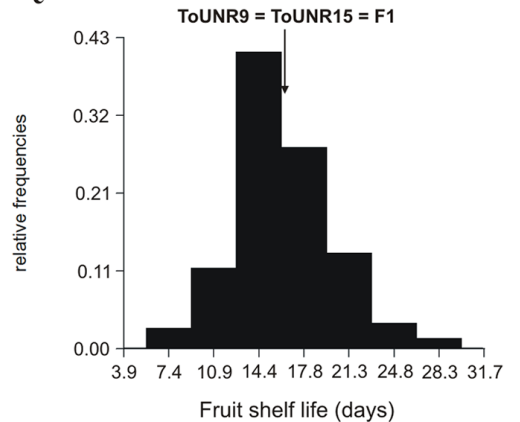

h

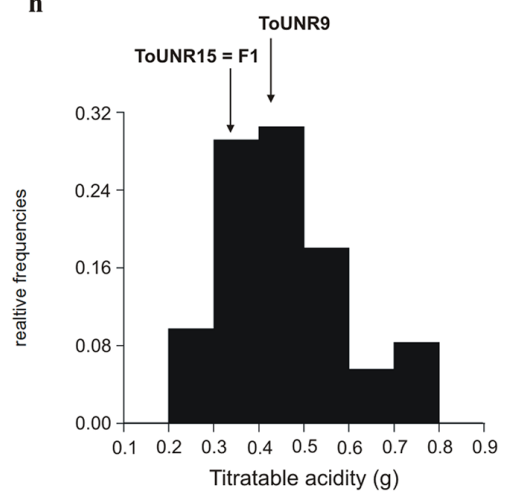

$\mathbf{k}$

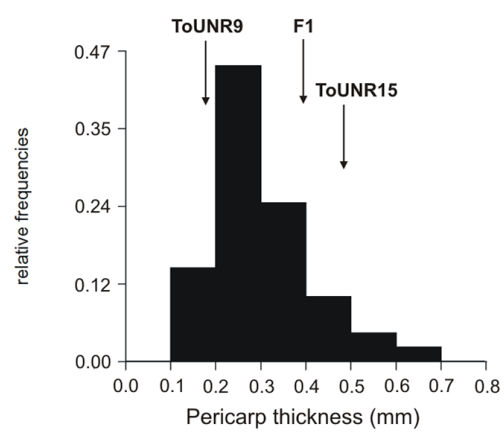

c

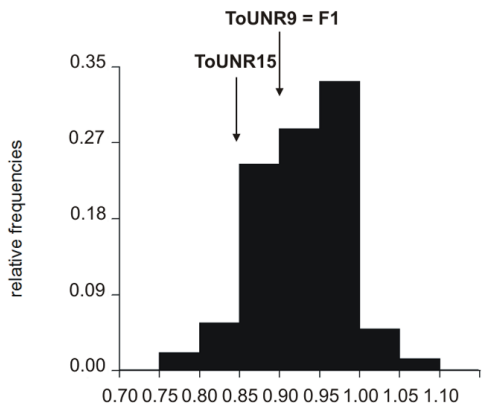

Fruit shape

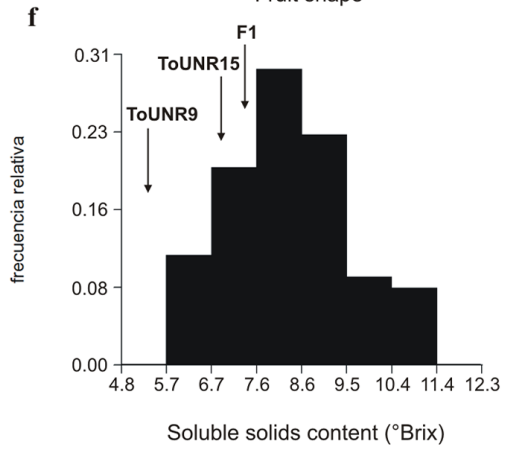

i

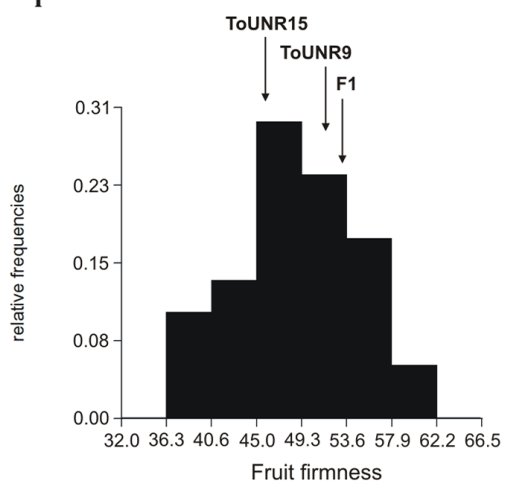

Figure 1. Frequency distributions for each phenotypic trait evaluated in $\mathrm{F}_{2}$ (ToUNR15 $\mathrm{x}$ ToUNR9) generation. Arrows indicates mean values of each trait in parents (ToUNR15 and ToUNR9) and the $F_{1}$. 
$\mathrm{pH}$, and TA (Tables1 and 2). However, associations for pericarp thickness, firmness and locule number, with intermediate values of genetic variability, were also found. A similar result was found for fruit shelf life in spite of being a trait with low $\mathrm{H}^{2}$. The occurrence of a band associated with more than one trait could be explained by pleiotropic effects or by a strong linkage between two or more QTLs underlying these different traits (Kearsey and Pooni 1996). Co-localized associations are frequent. In fact, co-localized association for soluble solid content and sugar content, fruit weight and locule number were also found by Xu et al. (2013) in an association mapping study for fruit quality traits of cultivated tomato and related species. Results from Tables 3 and 4 suggest that both types of DNA markers (SRAP and AFLP) allowed QTL detection. Polypeptide profiles were not useful to mark genetic regions that could be involved in the quantitative variation in this segregating generation derived from a $\mathrm{SCH}$. They would probably be more valuable if the parental genotypes were more divergent. DNA markers are more effective because they cover a higher proportion of the genome and can distinguish a larger amount of molecular polymorphism. For same traits QTLs were found using both SRAP and AFLP. From an operational point of view, the SRAP markers were simpler, less expensive and quicker. They can detect the same extent of associations but with a considerably smaller number of total bands compared to AFLP markers (214 against 735, respectively). Gene blocks due to recombination events together with a tight linkage were found by genetic linkage analysis (Figure 2). The genomic regions belonging to the same linkage group (LG) were produced by fragments inherited from first cycle parental genotypes. Nevertheless, some bands assessed in ToUNR9 and ToUNR15 and conserved in generation $\mathrm{F}_{1}$ (Mendelian inheritance in $\mathrm{F}_{2}$ ), were defined as de novo bands (Liberatti et al. 2013). Even if they were absent or monomorphic in Caimanta and LA722 (first cycle parental genotypes), inheritance was stabilized in the second cycle parental genotypes as well as in the segregating generation (see examples in LG1, LG2, LG3, and LG4 in Figure 2).

Table 2. Detected associations in $\mathrm{F}_{2}$ (ToUNR15 $\mathrm{x}$ ToUNR9) with SRAP (Sequence-related Amplified Polymorphism) markers (A) and AFLP (Amplified Fragment Length Polymorphism) markers (B)

A

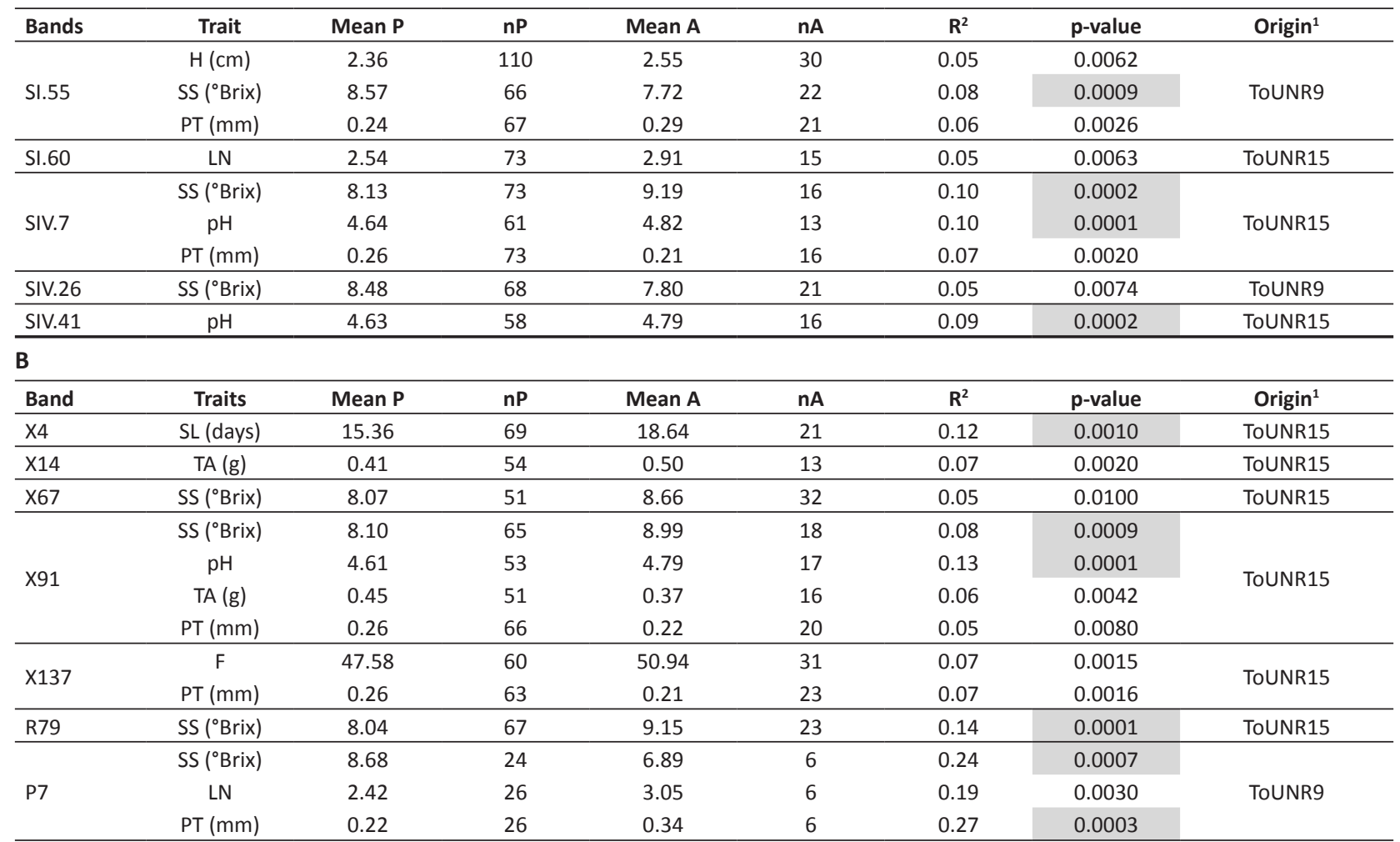

${ }^{1}$ Origin (parental genotype) of DNA amplification fragments are indicated. Mean P: mean value for $F_{2}$ plants with presence of band, $n \mathbf{P}$ : number of plant with presence of band, Mean A: mean value for $F_{2}$ plants with absence of band, $n A$ : number of plants with absence of band, $R^{2}$ : fraction of phenotypic variation, $p$-value: probability associated, H: fruit height, SS: soluble solids content, PT: pericarp thickness, LN: locule number, SL: fruit shelf life, TA: titratable acidity. 


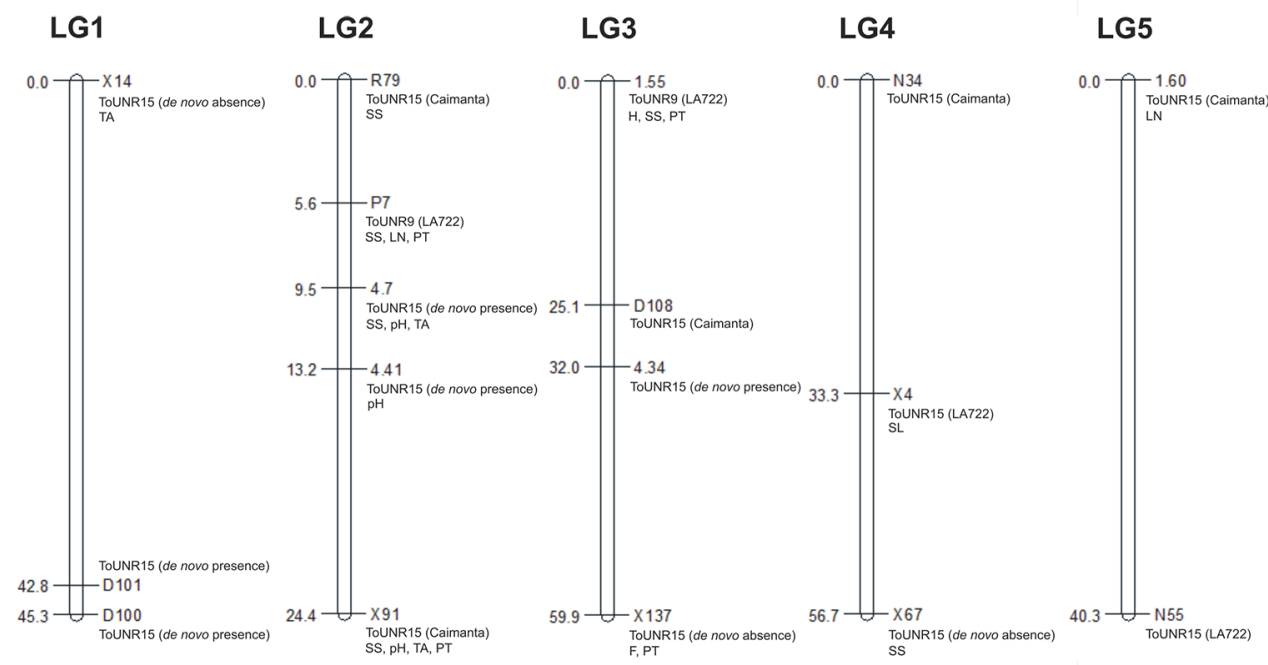

Figure 2. Linkage group (LG) constituted by molecular markers with Mendelian inheritance. The origin of molecular markers in second cycle parental genotypes (ToUNR15 and ToUNR9) and firstcycle parental genotypes (between brackets, Caimanta of S. lycopersicum and LA722 of S. pimpinellifolium) are indicated. The de novo bands were defined according to Liberatti et al. (2013). The phenotypic traits associated with the molecular markers are also indicated. TA: titratable acidity, SS: soluble solids content, LN: locule number, PT: pericarp thickness, H: height, F: firmness, SL: shelf life.

The five linkage groups spanned $226.6 \mathrm{cM}$ (about 15\% of the whole tomato genome, based on previous maps reported by Khialparast et al. 2013 and Tanksley et al. 1992), with a mean interval length of $13.3 \mathrm{cM}$ between markers. It was found that 17 of 26 (65\%) markers with Mendelian segregation belong to some linkage groups. The number of markers per linkage group ranged from 2 (LG5) to 5 (LG2). On average, 3.4 markers per group were detected. The LG3 was the largest $(59.9 \mathrm{cM})$ and $\mathrm{LG} 2$ had the smallest genetic linkage distances. Although all polymorphic polypeptides with Mendelian segregation were considered in the analysis they do not belong to any linkage group. The most interesting group was LG2, for being the shortest. During the first cycle of crosses, new gene blocks from chromosome regions of Caimanta and LA722 were created by recombination. They were conservatively inherited and located at LG2. Moreover, the markers belonging to this LG were associated with fruit quality traits (SS, $\mathrm{pH}, \mathrm{TA}, \mathrm{LN}$ and PT) in robust agreement with those observed in the parental RILs for these traits. This fact implies that ToUNR9 and ToUNR15 genotypes fixed alleles with opposite effects during the selection process. A similar result was found for pericarp thickness, a trait for which the QTL detected in LG3 had opposite effects on the linkage markers (X137 increases its mean value and SI.55 decreases it). These results are consistent with the breeding approach proposed by Bai and Lindhout (2007), who stated that early selection for fruit quality traits is rarely performed in crosses derived from wild germplasm, as many generations may be needed to remove the deleterious genes that accompany the introduced genes, due to linkage drag. When the parental lines reach a high level of homozygosity $\left(\mathrm{F}_{4}\right.$ to $\left.\mathrm{F}_{6}\right)$, crosses are made to test hybrids.

Phenotypic characterization of the two tomato RILs derived from an interspecific cross, the $\mathrm{F}_{1}$ generation ( $\mathrm{SCH}$ ) between them and the segregating $\mathrm{F}_{2}$ generation allowed the identification of genetic variability for several fruit quality traits. Different polymorphism levels were detected by polypeptide profiles, SRAP and AFLP markers, showing that the observed phenotypic differences are associated with gene variation. Only SRAP and AFLP markers were able to detect QTLS for fruit quality traits of agronomic interest. This study demonstrated the presence of new gene blocks by chromosome rearrangement and recombination. These results suggest that it is possible to go on with a tomato breeding plan to generate phenotypes with higher performance for fruit quality in the studied $F_{2}$ generation.

\section{ACKNOWLEDGEMENTS}

The authors thank the Agencia Nacional de PromociónCientífica y Tecnológica (ANPCyT) for funding the project (PICT 2004 (SECYT-FONCYT) (№ 08 25481)) and the Consejo Nacional de Investigaciones Científicas y Técnicas (CONICET) for scholarships. 


\section{REFERENCES}

Aharoni A and O'Connell AP (2002) Gene expression analysis of strawberry achene andreceptacle maturation using DNA microarrays. Journal of Experimental Botany 53: 2073-2087.

Bai $Y$ and Lindhout $P$ (2007) Domestication and breeding of tomatoes: What have we gained and what can we gain in the future? Annals of Botany 100: 1085-1094.

Castro HA, Galvez MJ, González SR and Villamil CB (2006) Protein composition of Cucurbita maxima and C. moschataseeds. Biologia Plantarum 50: 251-256.

Cravero VP, Martín EA and Cointry E (2007) Genetic diversity in Cynara cardunculus determined by SRAP markers. Journal of American Society of Horticultural Science 132: 208-212.

Di Rienzo JA, Casanoves F, Balzarini MG, Gonzalez L, Tablada M and Robledo CW (2001) Infostat. Versión 2001, Grupo Infostat, FCA, Universidad Nacional de Córdoba, Argentina.

Falconer DS and Mackay TFC (1996) Introduction to quantitative genetics. Longmans Green, Harlow, 494p.

Figueiredo AST, Resende JTV, Faria MV, Paula JT, Schwarz K and Zanin DS (2015) Combining ability and heterosis of relevant fruit traits of tomato genotypes for industrial processing. Crop Breeding and Applied Biotechnology 15: 154-161.

Garg N, Cheema DS and Dhatt AS (2008) Genetics of yield, quality and shelf life characteristics in tomato under normal and late planting conditions. Euphytica 159: 275-288.

Giovannoni JJ (2004) Genetic regulation of fruit development and ripening. Plant Cell 16: 170-180.

Grandillo S, Zamir D and Tanksley SD (1999) Genetic improvement of processing tomatoes: A 20 years perspective. Euphytica 110: 85-97.

Grimplet J, Romieu C, Audergon JM, Marty I, Albagnac G, Lambert P, Bouchet JP and Terrier N (2005) Transcriptomic study of apricot fruit (Prunus armeniaca) ripening among 13,006 expressed sequence tags. Physiology Plantarum 125: 281-292.

Hennig L, Gruissem W, Grossniklaus U and Köhler C (2004) Transcriptional programs of early stages of plant reproduction. Plant Physiology 35: 1765-1775.

Hills J, Lethenborg P, Li PW, Rahman RH, Sorensen H and Sorensen JC (2003) Inheritance of progoitrin and total aliphatic glosinolates in oilseeds rape (Brassica napus L.). Euphytica 134: 179-187.

Ipsilandis CG, Tokatlidis IS, Vafias B and Stefanis D (2006) Criteria for developing second-cycle hybrids in maize. Asian Journal of Plant Sciences: 680-685.

Kearsey MJ and Pooni HS (1996) The genetical analysis of quantitative traits. Chapman and Hall, London, 396p.

Khialparast F, Abdemishani S, Yazdisamadi B, Naghavi MR and Foolad M (2013) Identification and characterization of quantitative trait loci related to chemical traits in tomato (Lycopersicon esculentum Mill.). Crop Breeding Journal 3: 13-18.

Kosambi DD (1943) The estimation of map distances from recombination values. Annals of Eugenics 12: 172-175.

Lecomte L, Duffé P, Buret M, Servin B, Hospital F and Causse M (2004) Marker-Assisted introgression of 5 QTL controlling fruit quality traits into three tomato lines revealed interactions between QTLs and genetic background. Theoretical and Applied Genetics 109: 658-668.

Li G and Quiros CF (2001) Sequence-related amplified polymorphism (SRAP), a new marker system based on a simple PCR reaction: its application to mapping and gene tagging in Brassica. Theoretical and Applied Genetics 103: 455-461.

Liberatti DR, Rodríguez GR, Zorzoli R and Pratta GR (2013) Tomato second hybrids differ from parents at three levels of genetic variation. International Journal of Plant Breeding 7: 1-6.

Mahuad SL, Pratta GR, Rodríguez GR, Zorzoli R and Picardi LA (2013) Preservation of Solanum pimpinellifolium genomic fragments in recombinant genotypes improved the fruit quality of tomato. Journal of Genetics 92: 195-203.

Marchionni Basté E, Liberatti DR, Mahuad SL, Rodríguez GR, Pratta GR, Zorzoli R and Picardi LA (2010) Diallel analysis for fruit traits among tomato recombinant inbred lines derived from an interspecific cross Solanum lycopersicum $\times$ S. pimpinellifolium. Journal of Applied Horticulture 12: 21-25.

Michael TP and Alba R (2012) The tomato genome flashed out. Nature Biotechnology 30: 765-767.

Moyle R, Fairbairn DJ, Ripi J, Crowe M and Botella JR (2005) Developing pineapple fruit has a small transcriptome dominated by metallothionein. Journal of Experimental Botany 56: 101:112.

Pereira da Costa JH, Rodríguez GR, Pratta GR and Zorzoli R (2009) Influencia de genes exóticos sobre la vida en estantería y el peso del fruto de tomate. Agriscientia 16: 7-13.

Pereira da Costa JH, Rodríguez GR, Pratta GR, Picardi LA and Zorzoli R (2014) Pericarp polypeptides and SRAP markers associated with fruit quality traits in interspecific tomato backcross. Genetics and Molecular Research 13: 2539-2547.

Pratta GR, Zorzoli R and Picardi LA (2003) Diallel analysis of production traits among domestic, exotic and mutant germplasms of Lycopersicon. Genetics and Molecular Research 2: 206-213.

Pratta GR, Rodríguez GR, Zorzoli R, Valle EM and Picardi LA (2011) Phenotypic and molecular characterization of selected tomato recombinant inbred lines derived from a cross Solanum lycopersicum x S. pimpinellifolium. Journal ofGenetics 90: 229-237.

Rick CM (1978) The tomato. Scientific American 239: 76-87.

Rodríguez GR, Pratta GR, Zorzoli R and Picardi LA (2006) Evaluación de caracteres de planta y fruto en líneas recombinantes autofecundadas de tomate obtenidas por cruzamiento entre Lycopersicon esculentum y L. pimpinellifolium. Ciencia e Investigación Agraria 33: 133-141. 
Tomato second cycle hybrids as a source of genetic variability for fruit quality traits

Rodríguez GR, Sequin L, Pratta GR and Zorzoli R (2008) Protein profiling in $F_{1}$ and $F_{2}$ generations of two tomato genotypes differing in ripening time. Biologia Plantarum 52: 548-552.

Rodríguez GR, Pereira da Costa JH, Tomat DD, Pratta GR, Zorzoli R and Picardi LA (2011) Pericarp total protein profiles as molecular markers of tomato fruit quality traits in two segregating populations. Scientia Horticulturae-Amsterdam 130: 60-66.

Ruiz JJ, García-Martínez S, Picó B and Gao M (2005) Genetic variability and relationship of closely related Spanish traditional cultivars of tomato as detected by SRAP and SSR markers. Journal of American Society of Horticultural Science 130: 88-94.

Saliba-Colombani V, Causse M, Langlois D, Philouze Jand Buret M (2001) Genetic analysis of organoleptic quality in fresh market tomato. 1. Mapping QTL for physical and chemical traits. Theoretical and Applied Genetics 102: 259-272.

Shapiro SS and Wilk MB (1965) An analysis of variance test for normality (complete samples). Biometrika 52: 591-611.

Snedecor G (1964) Métodos estadísticos. Compañía Editorial, México, $593 p$.

Stevens ME, Kader AA and Albright M (1979) Potential for increasing tomato flavor via increased sugar and acid content. Journal of
American Society of Horticultural Science 104: 40-42.

Tanksley SD, Ganal MW, Prince JP, de Vicente MC, Bonierbale MW, Broun P, Fulton TM, Giovannoni JJ, Grandillo S, Martin GB, Messeguer R, Miller JC, Miller L, Paterson AH, Pineda O, Riider MS, Wing RA, Wu $W$ and Young ND (1992) High density molecular linkage map of the tomato and potato genomes. Genetics 132: 1141-1160.

Tanksley SD (1993) Mapping polygenes. Annual Review of Genetics 27: 205-233.

Terrier N, Glissant D, Grimplet J, Barrieu F, Abbal P, Couture C, Ageorges A, Atanassova R, León C, Renaudin JP, Dédaldéchamp F, Romieu C, Delrot $S$ and Hamd S (2005) Isogene specific oligo arrays reveal multifaceted changes in geneexpression during grape berry (Vitis vinifera L.) development. Planta 222: 832-847.

Tomato Genome Consortium (2012) The tomato genome sequence provides insights into fleshy fruit evolution. Nature 485: 635-641.

Xu J, Ranc N, Muños S, Rolland S, Bouchet JP, Desplat N, Le Paslier MC, Liang Y, Brunel D and Causse M (2013) Phenotypic diversity and association mapping for fruit quality traits in cultivated tomato and related species. Theoretical and Applied Genetics 126: 567-581.

Zhang Y and Stommel JR (2001) Development of SCAR and CAPS Markers linked to the Beta Gene in Tomato. Crop Science 41:1602-1608. 